\title{
LA VERDAD INEXISTENTE: ARQUEOLOGÍA Y REFLEXIÓN FILOSÓFICA
}

THE NON-EXISTENT TRUTH: ARCHAEOLOGY AND PHILOSOPHICAL THOUGHT

\author{
por \\ ENRIQUE LUIS DOMÍNGUEZ BERENJENO
}

RESUMEN En este trabajo analizamos tres paradigmas históricos y su aplicación en Arqueología: Neopositivismo, Estructuralismo y Teoría Crítica (o sea, la Nueva Arqueología y las arqueologías estructural y crítica). Intentamos demostrar cómo han sido más o menos solapados por el entramado epistemológico de las llamadas "Ciencias Naturales", hegemónicas desde la revolución galileanonewtoniana. Finalmente llegamos a lo que pensamos que son los límites de este análisis epistemológico, condicionado por la herencia filosófica de la Modernidad. Optamos así por un enfoque post-moderno y postulamos por tanto una redefinición de las categorías del "conocimiento científico" o, en último caso, su definitivo abandono.

\begin{abstract}
In this work we analyze three historical paradigms, and their application in Archaeology: Neopositivism, Structuralism and Critical Theory (that is, New, Structural and Critical archaeologies). We try to show how they have been more or less overlaped by the epistemological frame of the so-called 'Natural Sciences', hegemonic from the Galilean-Newtonian Revolution. Finally we reach what we think are the limits of this epistemological analysis, conditioned by the philosophical heritage of the Modernity. We choose so a post-modern approach and therefore postulate for a re-definition of the categories of the 'scientific knowledge' or, lastly, for a definitive withdrawal from them.
\end{abstract}

\section{INTRODUCCIÓN}

El Conocimiento nos permite poder hacer. Pero, ¿cómo se accede a él?O, mejor expresado, ¿es accesible? $\mathrm{Y}_{i}$ existe el Conocimiento verdadero? Todo esto puede resumirse en dos conceptos: Verdad y Conocimiento, los dos pilares básicos de la investigación epistemológica.

La Epistemología o Gnoseología es el intento de establecer las bases verdaderas del conocimiento (o cuando menos de acercarse a ellas). Se diferencia por tanto de la mera teoría, ya que aquélla es la que 
proporciona el marco de referencia a los desarrollo teóricos, que pueden ser alternativos dentro de una misma disciplina.

Una primera disyuntiva nos asalta rápidamente: ¿Conocimiento global o individual? Que optemos por una u otra alternativa nos sitúa bien en el campo del monismo epistemológico, también conocido como Enfoque General (que presupone la unidad intrínseca, a nivel fundamental, de todos los campos del Conocimiento) o bien en el campo del Enfoque Restringido o particularista, que atomiza la Epistemología en tantas alternativas como disciplinas consideremos.

Desde una perspectiva arqueológica, la investigación sobre los fundamentos del Conocimiento (o investigación fundacionalista sin más) nos plantea interrogantes que no pocos tildarán de sobrecogedores, y que de hecho se hallan aún casi anatematizados en ciertos círculos. No referimos a las ya clásicas cuestiones sobre la naturaleza de la Arqueología, su objeto de conocimiento y qué define a un arqueólogo, así como sobre la validez de las "teorías" que surgen en el seno de las escuelas arqueológicas y, en último término, la necesidad de que exista una Teoría Arqueológica (o múltiples).

Otra cuestión fundamental se centra en el modelo de disciplina que queremos construir. Una posición monista nos llevaría a buscar el modelo teórico fuera de la Arqueología, en lo que podríamos denominar una Matriz Epistemológica General. Sin embargo, veremos cuán peligroso es ello cuando ésta está viciada, como sostenemos que ocurre actualmente. Por contra, optar por el particularismo nos sitúa en la tesitura de construir nuestro modelo desde dentro de la disciplina, lo que presenta también considerables (por no decir insalvables) dificultades, pues un sistema cerrado (y optar por el Enfoque Restringido supone convertir la disciplina de referencia, la Arqueología en nuestro caso, en un sistema cerrado) no puede organizarse por sí mismo, ya que la Teoría General de Sistemas ha demostrado suficientemente que los sistemas cerrados tienden naturalmente hacia un grado cada vez mayor de desorden (o entropía), no hacia una mayor organización, posible únicamente cuando el sistema en cuestión es abierto, esto es, cuando está referenciado con respecto a un sistema mayor que lo abarque (Laszlo 1988). Ello, por consiguiente, nos reconduce hacia el Enfoque General o globalista, situándonos, como veremos, en una difícil posición.

Obviamente, nosotros partimos de la convicción de que es necesaria una investigación fundacionalista de la Arqueología (como de cualquier otra disciplina), a fin de que ésta deje de interpretar el aburrido e improductivo papel de Hamlet que lleva improvisando tanto tiempo. Igualmente, nos situamos en una postura que considera el conocimiento arqueológico como una faceta más del conocimiento histórico, por lo que creemos en la validez (y en la necesidad) de la aplicación a aquél de las reflexiones ' teóricas y epistemológicas que han venido experimentando los estudios históricos en las últimas décadas.

No intentamos con este artículo agotar todas las posibles alternativas de reflexión teórica en Arqueología. Asumimos que muchas opciones se nos quedan en el tintero, y que trataremos preferentemente aquéllas que han atraído nuestra atención en los últimos años. Ni somos objetivos ni hemos intentado serlo, sino que únicamente hemos creído conveniente aportar algunos elementos al cada vez más generalizado debate filosófico en Arqueología.

1. Que no "renovación", ya que ni deseamos fundar otra "nueva" Arqueología ni somos partidarios de esa manía que tenemos los historiadores de calificar de "nuevo" todo lo que meramente trata de poner en entredicho lo "viejo", las más de las veces recayendo en sus mismos errores (Hernández Sandoica 1995). 


\section{MÁS ALLÁ DE LA TRAMPA DE NEWTON}

El desarrollo epistemológico en Arqueología nació viciado, puesto que se referenció con respecto a una Matriz General invalidada (o quizás habría que decir "contaminada") por el fisicalismo, esto es, por el predominio del que a nivel teórico disfrutaron hasta principios del siglo XX las disciplinas físicomatemáticas (en resumen, lo que dio en denominarse Positivismo y, más recientemente, Neopositivismo). Como consecuencia, sucesivas escuelas de pensamiento arqueológico han caído una y otra vez en lo que podemos denominar la trampa de Newton, traducible por el deseo de ser asimiladas dentro del modelo fisicalista. En este apartado analizaremos tres corrientes que han supuesto tres fases de este problema:

- La Nueva Arqueología, salvajemente atraída y destruida por su afán "cientificista".

- El Estructuralismo, que pese a desarrollar algunas categorías propias persistió (y persiste) en tendencias pro-fisicalistas.

- La Teoría Crítica, que si en su desarrollo general fracasó, debido a planteamientos heredados en origen, en sus aplicaciones actuales augura ciertas posibilidades de renovación teórica.

\subsection{La Nueva Arqueología: la presa perfecta}

Prácticamente nadie niega hoy día el papel de la Nueva Arqueología (NA) estadounidense (con sus posteriores proyecciones europeas) como referente inexcusable de la toma de conciencia arqueológica. Este reconocimiento, sin embargo, no obsta para que a continuación prácticamente todos la critiquen salvajemente $^{2}$. Esta especie de relación amor-odio no deja de ser tan rocambolesca como todo lo relacionado con estos aprendices de brujo que fueron los neoarqueólogos.

La publicación por Lewis Binford (1962) de su paradigmático artículo supuso para la Arqueología la recepción de un explícito status ontológico (dicho en otras palabras, se dijo qué era). Bien es verdad que, para ello, negándose a sí misma, la Arqueología debía asimilarse a la Antropología, pero ello resulta explicable dentro del tantas veces señalado papel de la Arqueología en la investigación estadounidense ${ }^{3}$. En cualquier caso, lo importante es que la ontologización de la Arqueología predisponía el terreno para su inclusión en los circuitos de reflexión teórica (que sería lo más común) y epistemológica (menos habitualmente). Sin embargo, pronto comenzarían a surgir los problemas.

Si Binford había proporcionado una dirección clara al adscribir lo arqueológico a lo antropológico, siguiendo a su vez a Willey y Philips, sus seguidores (referencia inexcusable es el trabajo de Watson, LeBlanc y Redman 1971) clamaron por la construcción de una teoría propiamente arqueológica (lo que dio en denominarse procesualismo, actualmente un cajón de sastre). Así pues, podríamos pensar que la secuencia lógica del desarrollo neoarqueológico habría sido, desde los presupuestos epistemológicos de la Antropología (en la que ellos, no debemos de olvidarlo, incluían a la Arqueología), haber desarrollado una aplicación teórica individualizada para la subdisciplina arqueológica. Sin embargo, ello no ocurrió así. Por el contrario, los neoarqueólogos buscaron su Santo Grial fuera de las Ciencias Sociales. Esto podría hacernos pensar que creían en cierta clase de monismo o Enfoque General, y que tratarían de adaptar lo que hemos denominado Matriz General a la Arqueología. En cierto modo fue así, pero antes de considerar las consecuencias de este procedimiento merece la pena detenerse un momento.

2. Como ejemplo puede verse el arrasador comentario que le dedican Shanks y Tilley (1992), negándole prácticamente cualquier virtud, en una crítica que expresa claramente el ambiente antiprocesualista que se desata en ciertos círculos a partir de los setenta.

3. En pocas palabras: o se investiga a los pueblos indígenas (¿y qué es eso sino Antropología?) o no se investiga. 
Desde la revolución científica del siglo XVII, la epistemología especial de las ciencias físico-matemáticas fue solapándose sobre la Epistemología General, que acabaría siendo eclipsada por aquélla. Ello resultó de un complejo proceso socio-histórico derivado de los presupuestos ilustrados del progreso perpetuo y de la posibilidad para el Hombre de alcanzar la felicidad a través del triunfo de las ciencias y la tecnología, todo ello sustentado por los desarrollos liberal-burgueses del s. XIX. Como consecuencia, "Epistemología" se equiparó a "Filosofía de la Ciencia", dando en una situación aberrante que persiste hasta la actualidad (Bunge 1980 o Vicent 1985 son sólo dos ejemplos, aunque el último ha experimentado en los últimos años una importante evolución filosófica). Paralelamente, el concepto de "Verdad" se equiparó al de "verdad científica", y el carácter "científico" o "no científico" de una disciplina se convirtió en el criterio de demarcación para admitirla o rechazarla académicamente. En este contexto, el denominado "método científico" se idealizó al extremo, y su aplicación pasó a ser la condición sine qua non para la credibilidad de una teoría cualquiera.

Volviendo a nuestro tema, no es de extrañar, pues, que la NA cayese en el espejismo fisicalista y adoptase las bases epistemológicas de las disciplinas físico-matemáticas. Con ello se consumaba su caída, en parte consciente y en parte inconscientemente, en la trampa de Newton.

Obviamente, en la actitud de la NA convergían varios factores:

- Una falta de reflexión epistemológica seria.

- El deseo de acceder al reconocimiento de la comunidad científica (con lo que ello suponía de acceso a un mercado de trabajo copado por la vieja escuela).

- La búsqueda de unos criterios de objetividad que parecían harto demostrados (de cara al exterior) en el campo de las Ciencias Naturales.

¿Cuáles eran los presupuestos epistemológicos a los que se adhirió la NA? Básicamente componían lo que algunos denominan "epistemología irrecíproco-causal" (Van der Leeuw 1978), basada en:

- La consideración de las leyes causa-efecto como elementos básicos en la interpretación del mundo real.

- El carácter universal de dichas leyes causales.

- Un modelo de explicación nomológico-deductivo ( $\mathrm{mN}$-D), también denominado hipotético-deductivo ( $\mathrm{mH}-\mathrm{D})$, basado en la deducción de reglas de investigación y contrastación a partir de enunciados axiomáticos, esto es, de leyes generales preestablecidas con respecto al inicio del proceso de contrastación.

- El uso de la lógica deductiva como forma de derivar modelos de contrastación de las leyes establecidas por el $\mathrm{mN}-\mathrm{D}$.

Todo esto puede parecer relativamente inocuo, pero el problema radicaba en que se había impuesto a la Arqueología un modelo epistemológico especial que no era el suyo, sino el de la Física, la Matemática, etc. Las singularidades no se hicieron esperar, y la NA pronto se vio encerrada en un círculo vicioso cuyo único objetivo era el descubrimiento y aplicación de leyes deductivas a los problemas arqueológicos. Se estudiaban las características de las leyes, se desarrollaban tipologías legales y, siempre que se podía, se atacaba al inductivismo (el método opuesto al mH-D) y a las generalizaciones empíricas (Binford 1978). Se pasó, en definitiva, de la construcción teórica (objetivo inicial) a la construcción de leyes. Es así como se llegó incluso a proponer un método para establecer "leyes arqueológicas" " ${ }^{4}$ La NA caía así en la metodolatría más absurda.

Después de 1973, año considerado oficiosamente como el de la muerte de la NA (Hernando 1992) a raíz de las críticas de Flannery y Morgan, sus supuestos epistemológicos pervivieron de una forma implícita 5 .

4. Propuesta que, debida a Stickel y Chartkoff, no pasaba de ser sino una variante del mH-D (Stickel y Chartkoff 1973).

5. Ciertamente los neoarqueólogos nunca han sido muy dados a la explicitación, siquiera teórica, y recientemente Renfrew y Bahn (1992) proponían la integración de teoría y método, último y aberrante eslabón de una incompetencia teórica que lleva durando ya más de treinta años. 
La mayor parte de las discusiones pasaron a un nivel metodológico, aunque en realidad nunca habían ido mucho más allá, centrándose en la aplicación del mH-D. El único debate epistemológico explícito que pervivió fue el referente al uso del $\mathrm{mH}-\mathrm{D}$ como generador de leyes, y en este aspecto prácticamente todos lo neoarqueólogos coincidieron en reconocer sus pasados errores y en que el $\mathrm{mH}$-D "no provee de criterios para la generación y confirmación de leyes" (Read y LeBlanc 1978) ${ }^{6}$.

Resumiendo, podemos decir que la NA fracasó por varias razones:

- A un nivel general, por la asunción de unas bases epistemológicas especiales no arqueológicas (las de las disciplinas físico-matemáticas).

- A un nivel axiológico, de enunciados fundamentales, por la no correspondencia entre sus propuestas (construir una teoría arqueológica desde los presupuestos de la Antropología) y lo que realmente hicieron (intentar construir leyes basándose en un método mal aplicado).

- A un nivel particular, por la errónea interpretación y el erróneo uso que dieron al mH-D, un método que, por su parte, tampoco satisface las necesidades de la investigación científica (Vicent 1981; Feyerabend 1985).

Así pues, la NA abrió el camino a la discusión epistemológica en Arqueología, pero su deslumbramiento por el fisicalismo y la pretensión de cientificidad le impidieron ir más allá. Habría de ser su derrumbe, paradójicamente, el que permitiera la aparición de nuevas perspectivas en Arqueología.

\subsection{Entre ayer y hoy: las propuestas estructuralistas}

Aunque las líneas maestras del estructuralismo fueron puestas por Lévi-Strauss desde mediados de siglo, su plena aplicación en Arqueología tendría que esperar a la convulsión neoarqueológica, y sólo en la última década se han comenzado a clarificar sus bases epistemológicas, que pueden resumirse en:

- La convicción en la unidad básica de la estructura mental humana (que se convierte así en un punto de referencia).

— El uso del cálculo de probabilidades como forma de aproximación a la realidad (constituida por los rasgos comunes de los sujetos individuales).

- La consideración de que los objetos han de entenderse como morfemas o partes de un discurso elaborado por las interrelaciones mutuas entre estas partes elementales, discurso en el que importan tanto los morfemas como sus interrelaciones, por lo que, en definitiva, el todo (el discurso) es más que la suma de las partes (los morfemas u objetos).

- El uso de un modelo tipológico-funcional (mT-F), compuesto por un número variable de categorías generales elaboradas a partir de los rasgos comunes al rango de objetos considerado.

Pese a su oposición a los planteamientos de la NA, el estructuralismo recae en algunos de los fallos de aquélla. Resurge el problema de la objetividad del Conocimiento, tan insoluble como siempre, y como siempre concretado en dos posturas enfrentadas. Por una parte, aquéllos que consideran posible dicha objetividad sobre la base de afirmar que, independientemente de las opiniones subjetivas, los hechos son contrastables "científicamente" (Martín de Guzmán 1981). Por otra parte, aquéllos para los que el propio proceso de investigación (esto es, los prejuicios y la personalidad del investigador) alteran irremediablemente el objeto de conocimiento ${ }^{7}$.

6. Quizás si todo el mundo hubiese leído un poco más se habría evitado el fiasco. El propio Binford, citando a Hempel, uno de los padres del mH-D, llegaria a señalar posteriormente que "las leyes son inventadas, no descubiertas" (Binford 1978).

7. Este último enfoque se ha visto reforzado, desde el campo de las Ciencias Naturales, por el desarrollo de los conceptos filosóficos derivados de la física cuántica (Chic 1990). Un caso paradigmático es el constituido por el principio de incertidumbre de Heisenberg: de una partícula se puede conocer su momento (masa y velocidad) o su posición, pero no ambas cosas a la vez, 
El problema de la objetividad lleva al segundo gran punto de contacto con la NA, como es el recurso a un mH-D amplificado, el mT-F. Reconociendo las críticas que se hicieron a su aplicación por los neoarqueólogos, se opta por una mezcla de inducción y deducción ${ }^{8}$ que no deja de encerrar un evidente peligro de tautología, siempre implícito en la inducción, ya que se establecen leyes a base de observaciones empíricas, leyes que luego, evidentemente, son contrastadas por la realidad.

Quizás el aspecto más sugerente de la epistemología estructuralista sea la gramaticalización del objeto de conocimiento, esto es, el considerarlo como un texto. En este sentido, el arqueólogo funcionaría como intérprete-receptor de un discurso, anacrónico pero traducible. Esto último es importante, y los estructuralistas hacen hincapié en ello: los restos materiales de las culturas son entendibles, es más, tienen que serlo para que la Arqueología cumpla su objetivo. No deja de subyacer, sin embargo, cierta contradicción, pues a la par que se textualiza el objeto de conocimiento se nos advierte del subjetivismo inherente a cualquier discurso.

Más que positiva, por otra parte, es la atención que el estructuralismo arqueológico dedica a tres importantes cuestiones epistemológicas:

— La formulación lógica (ordenada) como necesidad de establecer criterios de contrastabilidad.

— La formulación semántica, que supone indispensable el establecimiento de un vocabulario científico en Arqueología ${ }^{9}$.

— La formulación axiológica, que se ocupa del planteamiento de las cuestiones éticas (qué está bien) y estéticas (qué parece bien).

Se echa de menos, sin embargo, la reflexión sobre otros aspectos, que siguiendo a Mario Bunge (1980) podríamos resumir en:

- Una explicitación más estricta de los presupuestos gnoseológicos que indique cómo se ha de descifrar el discurso que nos ofrece el objeto arqueológico.

- La clarificación sobre qué clase de leyes generales son las que han de sustentar las teorías derivadas de la epistemología estructural.

En definitiva, el estructuralismo arqueológico alcanza un desarrollo epistemológico relativamente autónomo, e introduce amplias expectativas de construir una teoría arqueológica consistente. Sin embargo, permanece lastrado por parte de las dificultades que afectaron a la NA, por lo que aún depende en demasía de los modelos físico-matemáticos de racionalidad investigadora.

\subsection{La reflexión liberadora de la Teoría Crítica (TC)}

La TC nace de la mano de Max Horkheimer en 1930, desarrollándose desde entonces en el seno de lo que se conoce como Escuela de Frankfurt (Lamo de Espinosa 1981). Aunque retomaremos posteriormente sus implicaciones con respecto a la renovación de las Ciencias Sociales y el pensamiento arqueológico en particular, nos centraremos ahora en sus presupuestos epistemológicos y sus objetivos iniciales.

Dentro del pensamiento original de Horkheimer, la TC desempeñaba el papel de una metateoría, lo que venía a significar que se constituía en la armazón epistemológica de un discurso teórico o de una agrupación de teorías. Para Horkheimer, la Filosofía de la Historia hegeliana había supuesto el último momento de unión entre Filosofía e investigación, tras el cual se habría abierto una brecha entre ambas

ya que la mera intervención del investigador con sus instrumentos de análisis lo impide. Otra cosa es que esto pueda extrapolarse a las Ciencias Sociales.

8. Ya conocida en la NA como inferencia fuerte (Stickel y Chartkoff 1973).

9. Ello ya ha conducido a algunos resultados (Estévez, Gasull, Lull, Sanahuja y Vila 1981), pero no deja de ser peligroso el avance hacia una formalización que acerca a la disciplina a la Matemática pero la aleja, como ya señaló Feyerabend (1985) de la Sociedad. 
formas de conocimiento, que cristalizarían en dos corrientes enfrentadas, el Neopositivismo cientificista y la Metafísica. Urgía, pues, restaurar dicha brecha para poder desarrollar una TC que examinase los fundamentos de la Sociedad, ya que la eliminación de la Filosofía del proceso investigador imposibilitaba ejercer cualquier tipo de crítica a los modelos establecidos (supuestamente amorales).

Epistemológicamente, la primitiva TC de Horkheimer se basaba en una crítica sistemática del Positivismo, tras lo cual se habría de aplicar un modelo interdisciplinar a fin de construir una auténtica teoría social. En este sentido, el horizonte epistemológico de la TC era bastante simple, fundamentándose en la undécima tesis sobre Feuerbach de Marx ${ }^{10}$.

Posteriormente, sin embargo, las convulsiones sociales provocadas por los totalitarismos europeos acentuaron ciertos defectos de base de la concepción de Horkheimer, especialmente un cierto reduccionismo histórico derivado del funcionalismo marxista, con lo que el programa multidisciplinar de construcción teórica acabó fracasando, derivando hacia conceptos como el de "reificación", tomado de Lucácks y aplicado a la evolución histórica de la Humanidad como un componente indispensable del control de la Naturaleza (que el Hombre cosifica para poder dominar) y aplicado posteriormente a las formas de dominación social (los dominadores cosifican a los dominados para someterlos). Este reduccionismo histórico-filosófico llevaría, paradójicamente, a la separación de la TC del ámbito de la investigación empírica, colocándola en uno de los campos que quería dejar atrás, el de la Metafísica.

En Arqueología, la TC no ha recibido atención hasta hace apenas una década (Shanks y Tilley 1987; Vicent 1991), y su aplicación ha usado la reelaboración que de ella hizo Habermas a partir de los sesenta. La influencia que sobre Habermas ejercieron otras corrientes, como la Antropología fílosófica, la Hermenéutica o el análisis linguístico nos hará retomarlo posteriormente, deteniéndonos ahora en reseñar las directrices básicas de la aplicación de esta TC "renovada" en Arqueología.

La TC explicita en Arqueología algo que ya reclamaba la epistemología estructuralista, como es el componente ético-axiológico. De hecho, se considera que el fin de la Arqueología (al igual que el de cualquier otra disciplina a la que se le apliquen los presupuestos de la TC) no ha de ser refugiarse en la interpretación de su objeto de conocimiento, sino trascenderlo, y de esta forma hacer una especie de retroalimentación que haga presente las relaciones sociales entre conocimiento e interés (en célebre frase del propio Habermas). Así pues, la Arqueología aparece como el medio por el que el arqueólogo, necesariamente comprometido por y con la Sociedad en la que se inserta, desvela, cual abogado del diablo, las relaciones de dominación social que condicionan el acceso al Conocimiento. Con ello se retoman las posiciones originales de Horkheimer y Marcuse, que veían a la TC (antes de su degeneración funcionalista) como una autoridad crítica de autoconocimiento social (Honneth 1990).

Podemos preguntarnos hasta qué punto una Arqueología que queda reducida a medio de denuncia (o de dominación) social no queda un tanto vacía de contenido. Evidentemente, ello depende del punto de vista ideológico desde el que lo consideremos, pero desde una postura comprometida no puede dejar de observarse que la TC proporciona un claro objetivo a la disciplina, las bases epistemológicas para un desarrollo teórico en una articulación interdisciplinar y, finalmente, la posibilidad de escapar definitivamente de la trampa de Newton.

10. "Los filósofos no han hecho más que interpretar de diversas formas el mundo, pero de lo que se trata es de transformarlo" (Marx y Engels 1970). 


\subsection{Límites del enfoque epistemológico}

Creemos que podemos convenir en que el enfoque epistemológico aporta medios válidos de análisis en lo referente a la reconstrucción y sistematización de los fundamentos de las "vías teóricas" en Arqueología (de las que, obviamente, nos hemos limitado a espigar algunas). Una mayor profundización nos permitiría analizar las propuestas estructuralistas de reconstrucción teórica, que creemos de gran validez con respecto al establecimiento de unos presupuestos básicos que nos permitan la comprensión interteórica a nivel interno de la disciplina ${ }^{11}$. Sin embargo, no disponemos de espacio para ello, por lo que remitimos al lector interesado a los trabajos de Quintanilla (1987a; 1987b), Echeverría (1988) y, fundamentalmente, al de Balzer, Moulines y Sneed (1987).

Ahora bien, pese a dichos aportes positivos del análisis epistemológico, llega un momento en que se nos presentan ciertas debilidades internas que nos hacen reflexionar sobre las auténticas posibilidades de una Gnoseología o Teoría del Conocimiento en sentido restrictivo, teniendo en cuenta que, por su propia naturaleza, la Gnoseología se ocupa del Conocimiento "verdadero", con lo que ello presupone de considerar formas privilegiadas (y exclusivas) de Conocimiento. El fundamento de la Epistemología en la existencia de una posición gnoseológica privilegiada nos revela cómo, en tanto disciplina, la Epistemología se ve lastrada por el concepto newtoniano de Absoluto. Por su desarrollo, la Mecánica newtoniana exigía la existencia de un Tiempo y un Espacio absolutos, que permitiesen referenciar en ellos la estructura del Universo. De igual forma, la posición gnoseológica privilegiada que presupone la Epistemología nos permitiría referenciar en ella (al situarnos en un punto de vista metateórico) todo el proceso de fundación y demarcación de los distintos ámbitos del Conocimiento (integrándolos así en lo que hemos venido denominando el Enfoque General epistemológico). Una crítica a esta visión del mundo, inevitable desde el encuadre que proporcionan los últimos desarrollos filosóficos (aquel que para algunos encierra la actual "crisis" de la Filosofía, abarcada por el fenómeno de la Postmodernidad), será el objetivo del siguiente apartado.

\section{ENFOQUES FINISECULARES}

La concepción newtoniana de un Tiempo y un Espacio absolutos, a la que antes hacíamos referencia, recibió un duro golpe a principios de este siglo, de la mano, fundamentalmente, de la Teoría Cuántica comenzada a desarrollar, entre otros, por Max Planck. Sin embargo, este derrumbe de la certeza absolutista en Física no se transmitió a otros enfoques teóricos igualmente fisicalizados. El concepto epistemológico de que efectivamente era posible una certeza absoluta permaneció, pues, como eje fundamental de numerosas disciplinas (lo que dimos en llamar la trampa de Newton). No será hasta los sesenta cuando diversas aportaciones comiencen a proporcionar los medios para salir del espejismo fisicalista-neopositivista que aún hoy día perdura a muchos niveles.

11. Ello nos llevaría, asimismo, a discutir las posibilidades de una formalización del lenguaje arqueológico. Aquí solamente apuntaremos que, frente a quienes puedan pensar en los peligros de una formalización excesiva o de una "matematización", no podemos sino hacer nuestras las palabras de Quintanilla (1987a) cuando afirma que "las objeciones contra la utilidad de la formalización sólo serían aceptables si se admitiera la identificación de una teoría con el lenguaje formal en que se formula". Con todo, nos oponemos resueltamente a un formalismo radical como el que propone Bunge (1980). 


\subsection{La restauración de un Enfoque General}

No nos cansaremos de repetir que, en el caso particular de la Arqueología, el fracaso de intentos teóricos como el de la NA se debió en buena medida a su errónea elección de base epistemológica. La contaminación de la Matriz General por el modelo físico-matemático newtoniano vició cualquier intento de recurrir a ella en busca de criterios gnoseológicos adecuados para otras disciplinas. Así pues, el primer paso de cualquier intento de restauración del Enfoque General que asuma como ciertos los inconvenientes que reporta el Neopositivismo ha de ser precisamente la lucha contra dicha hegemonía fisicalista. Ello supone, en parte, la crítica de los propios cimientos de la Sociedad actual, levantada en torno al mito de una "Ciencia" fundamentalista (en el pleno sentido religioso de la palabra) y, por tanto, exclusivista, en absoluto amoral y desideologizada, sino plenamente comprometida con el desarrollo del modelo capitalista (no en vano el origen del Capitalismo corre parejo a la Revolución Científica iniciada por Galileo y continuada por Newton).

En esta tesitura, quizás convenga traer a colación algunas de las ideas de P. K. Feyerabend. Teórico del anarquismo metodológico, Feyerabend ha orientado sus críticas precisamente contra el absolutismo gnoseológico que el concepto de "Ciencia" (mediatizado por el Neopositivismo) ejerce sobre las demás capas del Conocimiento y de la Sociedad. La aplicación de estas ideas nos permitiría establecer dos conclusiones:

- El método científico no es el conjunto de reglas fijas e inefables que los neopositivistas postulan. Creer esto es caer en una metodolatría similar a la que afectó a los neoarqueólogos más exaltados.

- Los supuestos epistemológicos enarbolados por el Neopositivismo ${ }^{12}$ tienen exactamente la misma validez que los del resto de las disciplinas. No existen, pues, formas privilegiadas de Conocimiento.

Llegamos, de esta forma, a un dilema fundamental. Si desde el principio de este artículo hemos abogado por la restauración de un Enfoque General no contaminado por el Neopositivismo, al negar cualquier situación gnoseológica privilegiada estamos erosionando precisamente la posibilidad de la existencia de un Enfoque General entendido al modo de la Epistemología tradicional. Urge, pues, buscar nuevas formas de Conocimiento.

\subsection{El "giro lingüístico" y el enfoque hermenéutico}

Algunas de las principales críticas hacia la Epistemología provienen de la Teoría Crítica (TC) de Jürgen Habermas, la Hermenéutica de Hans Georg Gadamer y el Post-estructuralismo hermenéutico de Jacques Derrida. Todas estas visiones se centran en el nuevo papel que han ido adquiriendo en las últimas décadas tanto la Hermenéutica como los enfoque linguíísticos (lo que se ha dado en llamar el "giro linguíistico") en Ciencias Sociales.

El enfoque hermenéutico contempla la vieja dicotomía diltheyana entre "explicación" (propia de las Ciencias de la Naturaleza) y "comprensión" (característica, según la visión del filósofo alemán, de las Ciencias Humanas) no como elementos aislados, sino como dos momentos de una misma totalidad, considerando esta realidad como una estructura circular, expresada en la idea de que lo singular debe de ser entendido en el Todo, pero el todo también en lo singular ${ }^{13}$.

12. Que son, no lo olvidemos, los de las ciencias físico-matemáticas pre-cuánticas, fundamentalmente la consideración epistemológica del Tiempo y el Espacio absolutos y el uso del método científico (neopositivista, por supuesto) como criterio de demarcación para establecer qué disciplina se "queda dentro" y cuál se "queda fuera" del "Santuario" de la "Ciencia Verdadera" (con mayúsculas, por supuesto).

13. Es así como "la comprensión de lo singular presupone una precomprensión del todo dentro del cual es comprendido; pero la comprensión del todo crece de la comprensión de los momentos singulares que se estructuran en la realidad" (Coreth 1972). 
$\mathrm{La} \mathrm{TC}$, con su incidencia sobre la determinación social del Conocimiento ${ }^{14}$, invalida las pretensiones de una objetividad que descanse en "la fuerza de la razón o en la posibilidad de contrastación" (Martín de Guzmán 1981), como pretendían, por ejemplo, los estructuralistas. Ello, sin embargo, no lleva necesariamente a una subjetividad como la postulada, por ejemplo, por Hodder (1987) ${ }^{15}$, sino al fin de un normativismo que impide la crítica fundacionalista (Vicent 1991).

Resultado de su determinación social, el conocimiento resulta, para Habermas, fruto de la interacción entre tres tipos de comprensión:

- La comprensión lingüística.

- La comprensión mutua.

- La comprensión hermenéutica.

Para Habermas, el desajuste entre las dos primeras provoca una comunicación distorsionada entre emisor y receptor. La Hermenéutica se ocuparía de resolver estos problemas de comunicación. En definitiva, lo que Habermas sugiere, aplicado al conocimiento arqueológico, nos lleva a la conclusión de que los datos arqueológicos, que son interpretados por el lenguaje, lo son siempre, por ello mismo, de forma parcial, partidista. Es en el ajuste del proceso de interpretación, pues, donde la Hermenéutica juega un papel fundamental.

El desarrollo de las ideas de Gadamer apunta en un sentido similar al de Habermas, aunque ambos se hayan criticado mutuamente (Montoro 1981). Para Gadamer, durante el acto de comprensión de un texto (y la calidad de texto es aplicable a cualquier objeto de conocimiento), el receptor proyecta el primer sentido que encuentra sobre todo lo demás ${ }^{16}$. Puesto que dicho primer sentido se manifiesta porque se aplican al texto unas expectativas previas, Gadamer concluye que cualquier texto se comprende desde una preestructura determinada ${ }^{17}$. La misión de la Hermenéutica sería prevenir que lo que se pre-comprende no sea arbitrario. Para ello, Gadamer hace uso del concepto de "pre-juicio", pero en un sentido etimológico, no peyorativo. Habría que desarrollar, en esta línea, un nuevo criterio de razón que acepte las limitaciones y condicionamientos del acto de la percepción, desechando así la idea de una Razón absoluta. Finalmente, se llega de este forma a la conclusión de que "el verdadero sentido de un texto está siempre determinado por la situación histórica del intérprete, y en consecuencia por todo el proceso histórico" (Gadamer 1977).

Pero quizás es Jacques Derrida el que realiza una labor más extensa de crítica de la Epistemología, por lo que nos detendremos un poco más en sus principales supuestos (Hoy 1988). Para Derrida, la Hermenéutica, como base de la crítica epistemológica, presenta una serie de características fundamentales:

- No existe un punto de vista privilegiado para el conocimiento, por lo que el significado deriva no del emisor, sino de la estructura del lenguaje, lo que lleva a múltiples lecturas posibles de un mismo sistema de fenómenos.

— La percepción está predeterminada por la teoría (o ideología) subyacente al intérprete. Paralelamente, se considera que cualquier acto de entendimiento puede ser asimilado a un proceso de lectura, por lo que ésta sustituye a la visión, que había sido el paradigma del Conocimiento epistemológico.

Es innegable la componente estructuralista del proceso, que recoge la ya conocida idea de que el todo es mayor que la suma de las partes.

14. Esto es, que cualquier acto de conocimiento está condicionado por el contexto social del sujeto cognoscente.

15. Aunque la subjetividad entendida al modo de Feyerabend (1985; González 1988) no deja de ser un eficaz remedio contra la omnipresencia de los acólitos del cientificismo de la peor calaña.

16. Esto es lógico: si comenzamos a leer un libro sobre Yacimientos arqueológicos de la Península Ibérica, encararemos el texto con la esperanza de que nos hablen de lo que tal título enuncia, y no de que el contenido sea de hecho una edición de Rinconete y Cortadillo.

17. Lo que nos remite a la determinación social del conocimiento habermasiana, abundando sobre las similitudes entre ambos autores. 
— No existen axiomas (proposiciones universales y autoevidentes), sino que la reflexión puede alterar los principios establecidos, puesto que cualquier entendimiento está lastrado por el autoentendimiento, y cambios en éste afectan a aquél ${ }^{18}$.

El Post-estructuralismo derridiano tiene un fuerte componente de rechazo hacia las vías muertas en las que se obceca la Epistemología, como serían fundamentalmente dos:

- La cuestión de la representación, esto es, si la mente y sus ideas representan adecuadamente la realidad. Derrida obvia el problema pasando de las categorías mentales a las lingüísticas (en las que la relación lenguaje-realidad posee unas reglas definidas por la Teoría Lingüística). Como consecuencia de la supresión del problema de la representación, también considera inútil seguir considerando la idea de "Progreso" como acumulación indefinida de conocimientos ${ }^{19}$.

- La cuestión del humanismo post-kantinao: Kant, al formular explícitamente la pregunta "¿qué es el Hombre?", condenó a la reflexión filosófica a otra vía muerta (el antropocentrismo metafísico), que ha resultado tan estéril como el debate de la representación. Derrida, coincidente en ello con Foucault y Heidegger, critica ese humanismo reduccionista que produce la afirmación de la conciencia constituyente establecida por Descartes. De esta forma, la mente no sería el instrumento de construcción del mundo, puesto que los seres humanos no serían trascendentes, sino sociales e históricos. Se apuesta, por tanto, por un humanismo revolucionario que elimine la dicotomía objetivo-subjetivo, retomando así de nuevo planteamientos estructuralistas.

La postura de Derrida la reencontramos, ampliada a todo el razonamiento epistemológico, en Anthony Giddens, que considera que las inacabables disputas epistemológicas han de ser abandonadas en pro de una reelaboración de las concepciones del ser y el obrar humanos, esto es, en pro de una nueva Ontología.

Aún podemos rastrear otra vía muerta de discusión en el debate demarcacionista, que se ha venido ocupando de la determinación de la "cientificidad" o "acientificidad" de las disciplinas. Hace ya tiempo que se viene difuminando ${ }^{20}$ la división entre Ciencia-No Ciencia ${ }^{21}$, aunque, en cualquier caso, al problema de la demarcación subyacen unas necesidades mucho más prosaicas, como son los recursos económicos que dentro del mundo académico supone el acceso al "pueblo elegido" del cientificismo (Vicent 1983) ${ }^{22}$. Mucho nos tememos que, en definitiva, debajo de toda la parafernalia demarcacionista se esconda un complejo centrado en el deseo de reconocimiento por parte de aquellas disciplinas que ven cuestionada su cientificidad ${ }^{23}$.

$¿$ Qué subyace a esta retirada (más que oportuna, pero retirada al fin y al cabo) de cuestiones hasta ahora fundamentales? La clave nos la puede dar uno de los planteamientos más sugestivos de Derrida, el concepto de "indecibilidad", que argumenta que los significados textuales son básicamente indecibles. Dicho de otra forma, cualquier elemento descontextualizado pierde su posible sentido. Ahora bien, ¿hasta qué grado puede descontextualizarse algo? Llevado al límite, cualquier disciplina puede descontextualizarse por completo. Derrida pone el ejemplo de una nota encontrada entre los papeles de Nietzche: "He olvidado

18. Y volvemos al concepto de determinación social del conocimiento, que de hecho es un tópico de gran parte de la crítica posmoderna.

19. Conclusión esperable, ya que el "Progreso" era uno de los pocos conceptos del paradigma newtoniano que aún permanecían en pie.

20. Tanto desde la crítica a la Epistemología como desde la Filosofía de la Ciencia, a partir de posturas tan diversas como las representadas respectivamente por Larry Laudan o por el propio Feyerabend (González 1988).

21. Que desde luego no puede ser establecida por el uso del método científico, puesto que éste no existe como conjunto blindado de reglas supremas. El actualmente postulado por los neopositivistas como "método científico" en modo alguno es válido, puesto que está construido desde disciplinas insertas en el sistema que son, dicho llanamente, "juez y jurado".

22. Esta faceta ya la experimentaron los miembros de la NA, y el resultado fue tanto más perjudicial para la Arqueología como beneficioso para los neoarqueólogos, que se vieron de resultas insertados en el sistema académico.

23. Caso de la Arqueología, pese a que hace ya veinte años Read y LeBlanc no dudaban, amparados por su optimismo legaliforme, de la cientificidad de la disciplina (Read y LeBlanc 1978). 
mi paraguas". Sin contexto, es una frase inexplicable, indecible. Ahora bien, $¿$ puede afirmarse tal indecibilidad para todo el resto de la obra nitzcheana, y, por extensión, para toda la Filosofía? Ello, aunque chocante, no deja de plantear una posibilidad: el abandono de toda la tradición filosófica. Que ello sea una alternativa válida o una mera manifestación de milenarismo está aún por ver.

\section{CONCLUSIONES}

Siguiendo a Richard Rorty (1995), somos de la opinión de que los textos no se interpretan, sino que se usan para determinados fines. Si en las páginas precedentes hemos analizado diversas alternativas conceptuales en la historia de la Arqueología desde un enfoque epistemológico, para a continuación resaltar los límites de dicho enfoque e introducirnos así en los senderos del "giro lingüístico" y la Hermenéutica, ello ha sido no tanto con fines historiográficos o didácticos cuanto para que el lector sea consciente de un hecho capital: la "Verdad" ha muerto. Desde este presupuesto epistemológico básico se comprenderá que está totalmente fuera de nuestros objetivos el plantear una alternativa. Por tanto, los puntos que a continuación expondremos no son sino el reflejo de la situación actual (noviembre de 1997) de nuestra reflexión teórica personal, que como tal es mutable y en absoluto pretende tener visos de validez universal. Siguiendo el formulario planteado por Felipe Criado (1987), podemos hacernos dos preguntas: ¿Qué es un arqueólogo? ¿Qué es la Arqueología?:

- Un arqueólogo debe de ser, fundamentalmente, un intelectual, y como tal tiene que poseer los elementos de juicio necesarios para diseccionar la sociedad en la que se inserta, para, en función de sus convicciones, criticarla o justificarla. En este sentido, el individualismo filosófico, el eclecticismo y la duda metódica se presentan como las herramientas más útiles en el proceso de autoconstrucción de unos patrones personales de reflexión teórica ${ }^{24}$.

- La investigación arqueológica es una investigación histórica. Sin embargo, el objeto de conocimiento de la Arqueología no puede ser ni el "Pasado" ni el "Hombre", que como categorías gnoseológicas las consideramos inexistentes. Por tanto, lo que estudiamos son elementos materiales presentes, que interpretamos según nuestra visión del mundo, reconstruyendo así un modelo de pasado.

- El espejismo fisicalista nos ha llevado a sobrevalorar el llamado "método deductivo", una falacia decimonónica en tanto en cuanto cualquier modelo operativo se origina en la preexistencia de unos datos mínimos, con lo que la inducción siempre se halla implícita en el proceso de construcción teórica ${ }^{25}$.

Somos conscientes de la cantidad de temas apenas esbozados a lo largo de este artículo. A modo de conclusión, permítasenos recapitular. A nuestro juicio, la herencia filosófica de la Modernidad es fundamentalmente idealista ${ }^{26}$. Ahora bien, si algo parece claro a estas alturas es que la Modernidad ha fracasado como proyecto. Las raíces ilustradas de la Filosofía actual no nos han conducido hacia un mundo mejor ni más feliz, pese a las optimistas proclamas sobre el Fin de la Historia (Fukuyama 1992) ${ }^{27}$. Se impone, por tanto,

24. La Arqueología sufre de una sobredosis de uniformidad mental, motivada por la adscripción de sus practicantes a las tradicionales escuelas de pensamiento, una adscripción que las más de las veces viene dada por los intereses académico-profesionales, cuando no por pereza intelectual. Nosotros optamos por rechazar las "fórmulas mágicas" y formar nuestro propio corpus teórico.

25. La alternativa es la revelación divina, pero aún no hemos llegado a tal grado de subjetivismo que la consideremos válida.

26. Incluso el materialismo no deja de ser sino un idealismo encubierto, al remitir en última instancia a un modelo interpretativo basado en formaciones socio-económicas ideales.

27. Y, desde luego, no nos hallamos a las puertas de la "Tierra Prometida" tanto por el liberal-capitalismo occidental (en sus versiones conservadora y socialdemócrata) como por el capital-comunismo practicado hasta hace poco en la ex-URSS y Europa oriental y todavía en China y parte del Tercer Mundo. 
la negación de esta herencia, y la búsqueda de nuevas (y múltiples) alternativas. En el camino tendremos que dejar nuestra caduca fe en realidades objetivas y verdades absolutas. Igualmente, tendremos que explicitar nuestro ideario personal (lo que nos obligará a forjarnos uno), y enfrentarnos finalmente con la cuestión seminal que atraviesa el pensamiento contemporáneo: ¿vale todo? Si ya no existe "la Verdad", ¿cualquier interpretación es válida? Nosotros creemos que no, y nos apoyamos para ello en la propuesta de una urgente remoralización de la reflexión intelectual. Ni la "ciencia" (sea lo que sea lo que entendamos por ello) es amoral ni la Postmodernidad es (no debe de serlo) el caos absoluto. Pese al peligro de subjetivismo debemos de abrirnos al debate, aunque previamente armados con nuestros propios prejuicios (en el sentido gadameriano) y nuestra propia moral. En definitiva, las historias son múltiples, pero (retomando un triste tópico de la postmodernidad "radical"), pese a todo, Auschwitz sigue siendo (debe de seguir siendo) una abominación.

\section{BIBLIOGRAFÍA}

ARTEAGA, O. y NOCETE, F. (1995): Presentación del Curso Preparatorio sobre Temas Actuales de la Arqueología social Iberoamericana (folleto), Sevilla, Departamento de Prehistoria y Arqueología de la Universidad de Sevilla.

BALZER, W., MOULINES, C. U. y SNEED, J. D. (1987): An architectonics for science: The structuralist program, Dordrecht, Reidel.

BENAVIDES, M. (1994): Filosofía de la Historia, Madrid, Síntesis.

BINFORD, L. R. (1971) [1962]: "Arqueología como Antropología”, Cuadernos de Antropología Social y Etnología 3: 41-56.

(1978): "On Covering Laws and Theories in Archaeology", Current Anthropology 19(3): 631-632.

BUNGE, M. (1980): Epistemología: Curso de actualización, Barcelona-Caracas-México, Ariel.

CLARKE, D. L. (1973): “Archaeology: the loss of innocence”, Antiquity 47: 6-18.

COLLINI, S. (comp.) (1995): Interpretación y sobreinterpretación, Cambridge University Press, Cambridge.

CORETH, E. (1972): Cuestiones fundamentales e Hermenéutica, Barcelona, Herder.

CRIADO, F. (1988): “Qué es un arqueólogo? ¿Qué es la Arqueología?”, Revista de Arqueología 82 (febrero): 5-7.

CHIC, G. (1990): Principios Teóricos en la Historia, Écija, Gráficas Sol.

GADAMER, H. G. (1977): Verdad y método, Salamanca, Sígueme.

ESTÉVEZ, J., GASULL, P., LULL, V., SANAHUJA, M. E. y VILA, A. (1981): “Arqueología como Arqueología: Propuesta para una terminología operativa”, I Jornadas de Metodología de investigación prehistórica. Soria 1981, Madrid, Universidad Complutense, Departamento de Prehistoria: 21-28.

FERNÁNDEZ MARTÍNEZ, V. (1991): Teoría y Método en Arqueología, Madrid, Síntesis.

FEYERABEND, P. K. (1985): ¿Por qué no Platón?, Madrid, Tecnos.

FUKUYAMA, F. (1992): El fin de la Historia y el último hombre, Barcelona, Planeta.

GIDDENS, A., et al. (1990): La Teoría Social, Hoy, Madrid, Alianza.

GILMAN, A. (1988): "Enfoques teóricos en la Arqueología de los ochenta", Revista de Occidente 81: 47-61.

GONZÁLEZ, W.J. (ed.) (1988): Aspectos metodológicos de la investigación científica: un enfoque multidisciplinar, Murcia, Universidad de Murcia.

HEMPEL, C. G. (1989): Filosofía de la Ciencia Natural, Madrid, Alianza.

HERNÁNDEZ SANDOICA, L. (1995): Los caminos de la Historia. Cuestiones de historiografía y método, Madrid, Síntesis.

HERNANDO, A. (1992): “Enfoques teóricos en Arqueología”, Spal 1: 11-35. 
HODDER, I. (1987): "La Arqueología en la era post-moderna", Trabajos de Prehistoria 44: 11-26. HOY, D. (1988): "Jacques Derrida", en Q. SKINNER (1988): 48-69.

JOHNSON, L. (1972): "Problems in 'Avant-Garde' Archaeology", American Anthropologist 74: 366-377. LAMO DE ESPINOSA, E. (1981): La Teoría de la Cosificación: De Marx a la Escuela de Francfort, Madrid, Alianza.

LASZLO, E. (1988): Evolución: La gran síntesis, Madrid, Espasa-Calpe.

MARTÍN DE GUZMÁN C. (1981): "Nociones epistemológicas y Arqueología prehistórica", I Jornadas de Metodología de investigación prehistórica. Soria 1981, Madrid, Universidad Complutense, Departamento de Prehistoria: 35-64.

MARX, K. y ENGELS, F. (1970) [1845]: Tesis sobre Feuerbach y otros escritos filosóficos, México, Grijalbo.

MONTORO, R. (1981): "Hacia la construcción de una teoría de la interpretación: en torno al debate Habermas-Gadamer", Revista Española de Investigaciones Sociológicas 14 (abril-junio): 47-68.

PAGÉS, P. (1983): Introducción a la Historia: Epistemología, Teoría y problemas de método en los estudios históricos, Barcelona, Barcanova.

QUINTANILLA, M. A. (1987a): "Temas y problemas de la filosofía de la ciencia (I)", Arbor (septiembre): 75-95.

- (1987b): "Temas y problemas de la filosofía de la ciencia (II)", Arbor (octubre): 101-111.

READ, D. H. y LeBLANC, S. (1978): "Descriptive Statements, Covering Laws, and Theories in Archaeology", Current Anthropology 19(2): 307-337.

RENFREW, C. (ed.) (1973): The explanation of culture change, London, Duckworth.

RENFREW, C. y BAHN, P. (1993): Arqueología (teoría, método y práctica), Madrid, Akal.

RORTY, R. (1995): "El progreso del pragmatista", en S. COLLINI (comp.) (1995): 96-118.

RUIZ RODRÍGUEZ, A., CHAPA, T. y RUIZ ZAPATERO, G. (1988): "La arqueología contextual: una revisión crítica", Trabajos de Prehistoria 45: 11-17.

RUIZ ZAPATERO, G. y VICENT, J. M. (1992): "Todo arqueólogo tiene algo de teórico: Una entrevista con Leo S. Klejn", Trabajos de Prehistoria 49: 11-25.

SHANKS, M. y TILLEY, C. (1992): Re-Constructing Archaeology, London and New York, Routledge.

SKINNER, Q. (comp.) (1988): El retorno de la Gran Teoría en las Ciencias Humanas, Madrid, Alianza.

STICKEL, E. G., CHARTKOFF, J. L. (1973): "The nature of scientific laws and their relation to lawbuilding in archaeology", en C. RENFREW (1973): 663-671.

VAN DER LEEUW, S. E. (1978): “Comment on Read and LeBlanc's 'Theories in Archaeology", Current Anthropology 19(2): 326.

VICENT, J. M. (1981): "Fundamentos para una investigación epistemológica sobre Prehistoria", I Jornadas de Metodología de investigación prehistórica. Soria 1981, Madrid, Universidad Complutense, Departamento de Prehistoria: 71-87.

(1982): "Las tendencias metodológicas en Prehistoria", Trabajos de Prehistoria 39: 9-53.

(1983): “¿Es la Arqueología una ciencia?”, Revista de Arqueología 32: 62-64.

(1985): "Un concepto de metodología. Hacia una definición epistemológica de Prehistoria y Arqueología", en Actas de las II Jornadas de Metodología y Didáctica de la Historia, Cáceres, Universidad de Extremadura, Servicio de Publicaciones, Departamento de Prehistoria y Arqueología: 55-72.

(1991): "Arqueología y Filosofía: La Teoría Crítica", Trabajos de Prehistoria 48: 29-36.

WATSON, P. J., LeBLANC, S. A. y REDMAN, C. L. (1971): El método científico en Arqueología, Madrid, Alianza. 